duction of a screen-grid between these electrodes, and the tetrode is thus available as an efficient high-frequency amplifier. It is also desirable to be able to vary the amplification of a stage without incurring the risk of distortion of the received signals, or of decreasing the effective selectivity. This is conveniently carried out by making the control grid spiral of a non-uniform pitch, so that the amplification depends on the grid bias voltage provided for the valve. Here we have the tetrode with variable mutual conductance between grid and anode circuits (variable-mu tetrode).

The above types of four-electrode valve suffer a limitation in use, which is due to secondary emission effects from the anode. This drawback has been removed by the introduction of a third, or suppressor, grid, which is located between the screen grid and the anode, and is in direct electrical connexion with the cathode. Thus we have arrived at the high-frequency pentode, which may or may not be provided with the variable-mu characteristic. The pentode is also available as an output valve specially designed to deliver audio-frequency power to the loud speaker. This valve is more sensitive and more efficient than the corresponding output triode, but necessitates rather more care in design and operation with a suitable output load.

Wireless receivers of the supersonic-heterodyne type require the provision of a stage in which local oscillations are generated, and of another stage in which these oscillations are suitably combined with the incoming signals to produce oscillations of the beat-frequency for subsequent amplification. The oscillation-mixing process may conveniently be carried out by using a hexode valve provided with two control-grids, one for the incoming signal and one for the local oscillations, and two screen grids to separate them from each other and from the anode. The introduction of a fifth grid will enable the separate triode oscillator valve to be dispensed with, and we thus have the heptode or penta-grid convertor, as a self-contained frequencychanger unit for supersonic-heterodyne reception. If it is desired to be free from the disadvantages of secondary emission, mentioned above, still another suppressor grid is required next to the anode, and we have arrived at the octode. An alternative arrangement of the electrodes in a frequencychanging valve, involving a triode-hexode in one envelope, was referred to in NATURE of October 13, 1934 (p. 577).

The introduction of the variable-mu amplifying valve described above has enabled a system of automatic volume control to be developed, by means of which overloading of the receiver by strong signals from a local station is avoided and also the effects of fading of weaker signals from distant stations are largely counteracted. These results are achieved by making the rectified signal provide the grid bias for the variable-mu valve and so control the amplification of the stage. To obtain the relatively large bias voltages required, it has become necessary to use a diode as detector ; further, in order to avoid loss of sensitivity in the receiver as a whole, separate detectors are desirable for the signal rectification and for the automatic volume control. These detectors are provided in the double-diode valve. Such a valve requires a relatively small amount of electron emission, and this may be derived from a portion of the cathode of the triode or tetrode used for audio-frequency amplification of the signals after detection. Thus we have arrived at the double-diode-triode and double-diode-pentode valves used in many commercial receivers of to-day.

The development of these multi-electrode valves has necessitated the use of considerable ingenuity in the design and construction of valve bases and sockets; for, except in certain high-frequency valves in which the connexion to one electrode is led out at the top of the glass envelope, all the electrode connexions are made by pins of the familiar type.

\title{
The Deutsche Physikalische Gesellschaft
}

$\mathrm{I}^{\mathrm{N}}$ $\mathrm{N}$ the year 1843, Magnus was professor of natural philosophy at Berlin and created a physical colloquium, or, as the obituary notice in NATURE of June 23, 1870, says, "Graduates and undergraduates assembled round him once a week, to enjoy what he called physical conversations. Here students in turn reported on investigations recently published, the master criticising the report, and opening a discussion on those points which appeared to deserve a fuller explanation". From all accounts, Magnus was an inspiring teacher, and it was under the influence of this colloquium that, two years later, in 1845, six young physicists-
Beetz, Brücke, Heintz, Karsten, Knoblauch and Emil du Bois-Reymond-founded a society which had as its object, first the communication of original papers, and secondly the issuing of an annual volume of reports on all publications of a physical nature which should have appeared during the year. The society went by the name of the Physikalische Gesellschaft zu Berlin, which in 1899 became the Deutsche Physikalische Gesellschaft, to indicate the nation-wide scope which it had attained. This Society is, then, celebrating this year, on January 14, its ninetieth birthday.

Of the names of the original founders, probably 
only those of du Bois-Reymond and of Beetz are familiar to theaverage reader nowadays, but in spite of the aristocratic indifference of some of the older representatives of science in Berlin, the Society grew rapidly. Among the fifty-three members who joined in the first year, we find the names of Dr. Helmholtz, Lieut. Werner Siemens and G. H. Wiedemann, while Kirchhoff and Clausius joined in the following year. A period of wonderful fertility was beginning for German physics, and practically every name of note during that period can be found in the lists of the Society.

In 1882 began the publication of the Verhandlungen, which, from being merely a record of meetings and short notices, later, in 1899, became a reputed journal for the printing of original papers, particularly valued for its quick publication. Meanwhile, the Fortschritte der Physik, published by the Society, became celebrated for the care and accuracy of its short abstracts of original papers in physics appearing in all countries. The fifty years celebration held in Berlin in January 1896 under the presidency of one of the founders, $\mathrm{du}$ Bois-Reymond, gave evidence of the prosperity of the Society, the membership of which then numbered about three hundred. The first series of photographs taken by Röntgen with his newlydiscovered rays was shown, and experimental demonstrations were given by, among others, E. Warburg, Arons, Aschkinass, Neesen, Rubens, Goldstein, Nichols, W. Wien and F. Kurlbauma very respectable list of names!

The new life of the Society, as the Deutsche Physikalische Gesellschaft, may be said to have been initiated under the influence of a discourse which Planck - a name long respected and beloved among physicists the world over-gave in December 1900 on the laws of radiation. His famous paper in which the conceptions of the quantum theory were first given to the world appeared a few months later. On the experimental side Goldstein and Rubens were addressing the Society on the fundamental investigations for which their names are best known. At the beginning of the War, the Society numbered more than seven hundred members, and the Verhandlungen were publishing papers of the first importance.

After the War, the Society initiated fundamental changes, which increased its influence both inside and outside Germany. Local branches were founded in all the chief centres of physical research throughout the country, and, in conjunction with the newly founded society for technical physics (Deutsche Gesellschaft für technische Physik, in the foundation of which, if I may obtrude a personal note, my old friend Hausser, whose death in 1933 at the early age of forty-seven years was so widely lamented, played a prominent part), yearly meetings were arranged, somewhat similar to our British Association meetings, but for physics only. The most recent of these meetings was held last September at Bad Pyrmont, and nearly five hundred physicists attended.

Changes which were widely felt outside Germany were made in the publications of the Society. There were in 1920 two extensive publications which gave abstracts of the world literature in physics; the Fortschritte der Physik and the Beiblätter of the Annalen der Physik. In place of these a single publication was issued, the Physikalische Berichte, which has attained a high reputation, outside as well as within Germany. The abstracts are, in general, exceedingly good, and appear promptly. In the same year, 1920, the Verhandlungen were discontinued, and in their place appeared the Zeitschrift für Physik, under the auspices of the Society. This publication is so well known to physicists in Great Britain as not to need commendation.

The Society is a powerful agent for the promotion of physical knowledge and for international accord and co-operation in the search for scientific truths. It now numbers some fourteen hundred members, of whom almost a third live outside Germany. Its work was never more important than now, and on its ninetieth birthday, which is being celebrated in Germany as a jubilee, it will receive the congratulations and good wishes of physicists of all nationalities.

E. N. da C. ANDrade.

\section{Obituary}

Dr. Theobald Smith, For.Mem.R.S.

W ITH the death on December 11 of Dr. Theobald Smith, there has passed away a great figure in the science of animal pathology. Much of his life was spent in research on veterinary science, and his work illustrates the natural intimate connexion between human and veterinary medicine, for his researches were of so accurate and fundamental a character that they made far-reaching additions to knowledge of disease both in man and the lower animals. The breadth of his outlook was remarkable and many branches of pathology have been enriched by his keen insight.

Theobald Smith was born at Albany, N.Y., in 1859, and after taking the degree of Ph.D. at Cornell in 1881 and of M.D. at Albany in 1883, he was appointed director of the Pathology Laboratory of the Bureau of Animal Industry in the U.S. Department of Agriculture in 1884, and his earliest work was recorded in the annual reports of that department. 